\title{
Teaching Practices and Knowledge Base of English as a Foreign Language Teachers' Communicative Language Teaching Implementation
}

\author{
Anchalee Jansem ${ }^{1}$ \\ ${ }^{1}$ Faculty of Humanities, Srinakharinwirot University, Thailand \\ Correspondence: Anchalee Jansem, Faculty of Humanities, Srinakharinwirot University, Sukhumvit 23, Bangkok, \\ Thailand.
}

Received: November 13, 2018

doi: $10.5539 /$ ies.v12n7p58
Accepted: January 15, 2019 Online Published: June 29, 2019

URL: https://doi.org/10.5539/ies.v12n7p58

\begin{abstract}
This small scale study aimed at identifying (1) the characteristics of teaching practices in CLT classrooms, (2) teachers' opinions underlying such practices, (3) their positions while adopting CLT, and (4) a knowledge base used as a framework of CLT implementation. Eight Thai teachers who regarded themselves as CLT proponents voluntarily took part in this study. Data collected via classroom observations and post-teaching semi-structured interviews indicated that CLT involved four common features including promoting 'small talk' in the target language, beginning the lesson with the combination of lead-in and presentation strategies, positively reacting to students' linguistic errors, and emphasizing semi-communicative activities. The participants' opinions underlying CLT implementation centered on playing multiple roles including lesson designers, class managers, and English users with certain levels of English proficiency. Content, pedagogical content, and subject matter knowledge served as their major elements of the knowledge base for teaching when conducting CLT lessons.
\end{abstract}

Keywords: communicative language teaching, teaching practices, knowledge base

\section{Introduction}

\subsection{Background}

English language teaching is a field that integrates theories in education, linguistics, and other disciplines with an aim to develop teaching and learning English in all contexts (Davigon, 2007). In the last four decades when the implementation of traditional teaching methods has declined, Communicative language Teaching (CLT), in contrast, has been regarded as one of the most appropriate and effective approach worldwide. As identified in research and seminal textbooks in the field of language education, a significant goal of CLT is to promote communicative competence (Brown, 2007). Hymes (1972) proposed that language competence embraces linguistic, sociolinguistic, pragmatic, and strategic competence individuals need for effective communication. His seminal concept has strongly guided the overall policy of language education since then.

Practically, instead of being a constant approach to language teaching, the underlying principles of CLT are diverse and yield various interpretations. Yet the concept of promoting the use of language rather than merely the mastery of grammatical rules always exists. In short, in addition to accuracy, fluency is a paramount. A wide range of interpretations have resulted in a variety of pedagogical implementation that can be grouped into two major versions (Howatts, 1984 cited in Liu, 2015). While a strong version aims at learning a language through communication to master in that target language, a weak version focuses on using the language to communicate. These different versions also affect differing teaching and learning practices under the same or related communicative approaches.

In Thailand, English language teaching has undergone continuous transforms guided by the principles of CLT and Thai students' as well as workforce employees' unsatisfactory English skills. For example, Office of Basic Education Commission (OBEC) (2015), the government sector responsible for K-12 education, has revised the national curriculum with significant changes about teaching, teacher development, and assessment to be aligned with CLT. In addition, a national policy issued by Higher Education Commission indicates that university graduates' English competence must meet a minimum requirement. However, English proficiency performed by Thai graduates has not been satisfactory (Frederickson, 2015). Hence, English curriculum implementation, with 
teaching practice in particular, is unavoidably being challenged. One frequently asked question is how English has actually been taught while CLT -based English curriculum is claimed to be the pillar. This study, therefore, investigated and uncovered, rather than evaluating, CLT implementation in English classroom settings in natural contexts in Thailand. Also, English teachers' perceptions about their roles and beliefs as well as a set of knowledge base were explored and presented to explain underlying reasons for the way they implemented CLT in naturalistic settings.

\subsection{Communicative Language Teaching}

Communicative language teaching (CLT) became apparently popular as an alternative to teaching methods criticized as not promoting real communication. The concepts underlying CLT originate from Hymes's notions of communicative competence that integrates a variety of knowledge and performance result in effective communication. With Hymes' concept as a paramount, the goals of CLT center around four strands of communicative competence: grammatical, sociolinguistics, discourse, and strategic sub-competences (Canale \& Swain, 1980; Richards, 2006).

With the popularity and emphasis on appropriate use and usage of language for communication, CLT has been adopted as a mainstream approach to language teaching, as seen through communicative language curricula, materials, assessment, and other related factors in education. Richards (2006) identified ten core assumptions of CLT implementations that can be concluded into the following highlighted characteristics: meaningful interaction, opportunities for meaningful negotiation, content engagement, multi-skills, and errors as a product of creative language use, diverse learning rates, communicative strategies, and teachers as facilitators.

Sharing similar principles about language and communication, CLT, nonetheless, keeps evolving and appears to add more but variant emphases. For example, one camp believes that CLT prioritizes meaning and linguistic functions for communication rather than form. In contrast, the opponents still support focuses on both (Spada, 2007). As such, due to a broad concept and set of goals instead of prescribed teaching procedures, the implementation of CLT yields differing teaching practices and findings. Spada argues that the re-conceptualization and future implementation of CLT could be an urgent issue.

While CLT has been proved to be effective in a number of educational contexts, its limitations have been discussed so far. For example, Savignon (2018) concludes that CLT yielded positive outcomes regarding language proficiency. On the other hand, Bax (2003), Butler (2011), and Littlewood (2013) synthesized the challenges indicated in a number of studies. These include, for instance, classroom management, unfamiliar activities, the discrepancy between the void of contextualization, mismatched concepts, inconsistent practices, and irrelevant testing policies, and some stakeholders' resistance. Teaching practices, theories, and teachers' attitudes toward CLT also show incongruence (Coskun, 2011). Teachers' practices and beliefs were also found to contradict the philosophy of CLT (Rahman et al., 2018). A few recent studies concluded that a number of factors that negatively impact CLT implementation include teachers' understanding of CLT, educational contexts, values of language teaching and learning, and available resources to teacher's language proficiency and knowledge. Other studies also presented critical findings and discussions pinpointing the inappropriateness of universal principles of CLT (Hiep, 2007; Jeon, 2009). Taken together, these studies provide an overview of CLT implementation. Nonetheless, due to an urge for both the adaptation and an understanding of CLT in practice, this study was designed to provide additional information presented through the research findings.

\subsection{Language Teachers' Knowledge Base}

It is essential that teachers possess sufficient knowledge to carry out teaching practices. A knowledge base in general includes knowing what and how to teach categorized into that of content, general pedagogy, curriculum, learners, educational contexts, educational goals, and pedagogical content (Shulman, 1987). For language teachers, these sub-categories are the construct of each teacher's expertise, understanding, awareness, knowledge, and skills utilized when carrying out teaching practices (Faez, 2011). Day (1993) viewed content, pedagogic. Pedagogic content, and support knowledge as accumulated knowledge base. Similarly and with added categories, Richards (1998) notes that possessing theories of teaching, teaching skills, communication skills and language proficiency, subject matter knowledge, pedagogical reasoning and decision making, and contextual knowledge represents aspects of knowledge base. Yang (2011) added two more aspects: knowledge of self and of assessment.

Recent research points out that pedagogical content knowledge plays the most prominent role in language teaching. In a pioneer study (Gatbonton, 2000) and subsequent research (Borg, 3003; Mullock, 2006), language teachers have been found to substantially have pedagogical thoughts concerning, for instance, language management, instructional flow, and knowledge of students. These thoughts were found to direct teaching practices. 


\subsection{Theoretical Framework}

To conceptualize CLT practices in natural settings, socio-cultural theory and teachers' knowledge base theory serve as the framework of this study. According to Vygotsky's sociocultural theory, an individual learns and behaves socially through complex interaction toward the co-construction of learning and life experience. This implies that an individual's behavior, knowledge formation, and values can be reconstructed in interweaving processes. In the same vein, Hudson et al $(2016$, p. 28) argue that social conditions influence 'workplace learning and practice.' That is to say, sociocultural theory can be a framework for explaining teachers' teaching practices and instructional beliefs.

\subsection{Aims of the Study}

In context of the implementation of CLT, this study was conceptualized to investigate EFL teachers' practices in classroom in naturalistic settings. The aims of the study include (1) to explain teachers' ELT practices, and (2) to identify underlying reasons for the teaching practices.

The research questions that guided the investigation were:

1) What are the characteristics of teaching practices in CLT classrooms?

2) What are the teachers' beliefs in communicative language teaching underlying the teaching practices?

3) How do the teachers position themselves when adopting CLT classrooms?

4) What aspects of teachers' knowledge base influence CLT implementation?

\section{Methodology}

This qualitative study utilized two main data collection methods: classroom observation and semi-structured interviews. Eight teachers of English accepting to adopt CLT to guide their teaching practices from four secondary schools volunteered to be the participants. Each of them was observed and videotaped for 2 hours followed by a semi-structured interview at the completion of each. For the richer information and some unclear understandings of the responses, the researcher conducted informal phone interviews with 3 participants.

\subsection{Participants}

The participant recruitment leaned toward purposeful selection with a criterion regarding CLT advocates. The preliminary stage dealt with seeking teachers who, based on their justification, implemented CLT and the permission to carry out data collection in naturalistic settings. Initially, twenty-one teachers volunteered to be the participants in this study. The second stage mainly related to selecting those willing to be both observed and interviewed via, if possible, various communication channels. The last stage of participant selection yielded eight teachers who strongly agreed that they regarded CLT as the framework for teaching and learning. Objectives, teacher's roles, learners' roles, classroom environment, learning materials, and assessment techniques were acceptably to be aligned with the CLT principles. All eight participants' English teaching experience range from six to twenty years as presented as follows.

\subsection{Data Collection and Analysis}

Data collection took place at four different sites: two secondary schools and one elementary school in Bangkok and one secondary in a neighboring city. Data in this study comprised recorded and transcribed eight teachers' (1) teaching practices, both verbal and non-verbal, and (2) responses to one-on-one semi-structured interviews. The recording took place concurrently with each classroom non-participatory observation of each teacher in naturalistic settings. Similarly, each 20-minute interview, 16 times in total, administered by the researcher was audio recorded.

Each source of data was transcribed, analyzed using open-coding and axial coding (Corbin \& Strauss, 2008), and crystalized to answer the research questions respectively. The axial coding also partly involved the use of directed content analysis (Hsieh \& Shannon, 2005) to categorize data relevant to key features of CLT and knowledge base. In doing this, Richards's $(1998,2006)$ ten core assumptions of CLT and knowledge base framework serve as flexible lenses for the data analysis processes.

\section{Findings}

\subsection{What Are the Characteristics of Teaching Practices in CLT Classrooms?}

Teaching practices, both directly and indirectly displayed in 16 English classes, indicated four common features: promoting 'small talk' in the target language, beginning the lesson with the combination of lead-in and presentation strategies, positively reacting to students' linguistic errors, and emphasizing semi-communicative 
activities. These characteristics captured during different phases in each lesson observed represented what the teachers did, when implementing CLT in naturalistic settings.

\subsubsection{Promoting 'Small Talk' in the Target Language}

Small talk as part of post-greetings verbal interactions was explicit in all observed classes, with varied topics relevant to current news and school activities. For example, the following excerpt indicates small talk that followed the turns of greetings:

Teacher A: I'm fine. Ok, sit down. Ok, who was late this morning? I saw you sitting in a row of late students. Right?

Students: The same. Are you surprised? Don't you really know who was late?

Teacher A: (laugh). Oh, ok, I shouldn't have asked you.

Similarly, another teacher mentioned about the heavy traffic over the weekend, saying,

Teacher E: Did you guys stay home or visit downtown over the weekend? I went to Baan Mai to just eat lunch. Gosh, I got stuck in the traffic for almost 30 minutes. I think our city is not a good place to live anymore.

Student: I went to Robinson. I saw a lot of traffic too. Our town is like Bangkok, with traffic jams everywhere.

Students: (laughter) So we should go to Bangkok, running away from the traffic here.

Interestingly, all the teachers mostly started and maintained small talk in English, promptly using communication strategies such as speech modification when needed. Yet students' responses in English were minimal, slipping into Thai completely before the end of each discussed subject. In between, a number of strategies used to promote continual responses in English seemed abundant. Teachers themselves left small talk when inserting transitions into the beginning of the lesson.

\subsubsection{Combining Lead-In and Presentation Strategies}

Lead-in techniques integrated with the presentation phase always served as signposts of the beginning of each lesson. In doing this, all teachers drew students' attention to prompts, encouraging students to give oral responses associated with vocabulary, grammar, and topic directly related to the key theme of the lesson. These seemed to direct students to bring about their background knowledge related to the themes of the lesson. These included showing pictures, relia, video clips, and using guessing games. Verbal interactions at this stage seemed to be guided by each teacher's leading roles while students only gave responses. That is, most of them ignored off-topic responses leading to the end of verbal interactions.

In all observed classes, the presentation stage can be divided into 2 mini phases: (1) an emphasis on target vocabulary via the teacher's oral initiation turn and the completion of an IRF discourse; and (2) open discussion to pave the way to the beginning of the major phase of skill practice. In doing this, most teachers, especially Teachers $\mathrm{C}$ and $\mathrm{H}$, maintained the use of English.

\subsubsection{Positively Reacting to Students' Linguistic Errors}

One of the most noticeable features of teaching practices was error treatment. In general, all teachers were found to positively react to students' errors found in linguistic production. Recordings indicated that errors existed in verbal interactions, thoroughly in each observed class. Surprisingly, based on the teachers' reactions, no errors were treated as serious mistakes. Instead, they paid attention to the meanings, providing cues for error realization later. Just in a few scenarios, especially during vocabulary and grammar practices, the teachers repeatedly directly reminded the students of errors, expecting immediate corrections. For example:

Teacher B: Ok, good, good. While I was walking to school, I saw a dog. How about you? Tell me about when you were walking to school.

Student 2. When I walking to school, I saw people.

Teacher B: You saw people (laugh). When you were walking, you can say when I was walking. Ok.

Can you say that again? Was walking.

In addition to reacting to students' errors through friendly negative feedback, most teachers did not hesitate to provide clues to facilitate appropriate output, concerning both grammaticality and appropriate word choice. In 
short positive reactions to errors included verbal and nonverbal acceptance as well as linguistic assistance.

\subsubsection{Using Semi-Communicative Activities}

Activities requiring students to use English while interacting with classmates, exchange information, and present their complete work were evident in all observed classes. Yet the duration of each activity varied depending on the goals of each lesson and students' level of participation. For example, in one two-turn activity, students worked in pair taking turn orally asking about their inspiration. The first one said, "One day I will be a famous star. How about you?" The other had to reply using an adjective and a noun about a career. This brief activity was preceded by a reading comprehension and a grammar revision on the different usage between future simple and present progressive tenses. Similarly, once each group of students had finished their forest saving project, the representative presented the group's sentences to convince the public, both showing the written slogan and explaining detailed plans regarding how and where to display the campaign.

In short, almost every communicative activity served as either practice or production stages of all observed classes. In doing this, students applied linguistic forms into mainly speaking in either dyadic or group interactions.

\subsection{What Are the Teachers' Beliefs in CLT Underlying the Teaching Practices?}

Interview responses provide a clearer concept of CLT perceived by all eight participants. The teachers' beliefs underlying both their teaching practices and awareness can be grouped into (1) speaking as the priority of communication, (2) face-to-face dyadic interaction as communication practice, and (3) form and meaning as essential elements of teaching and learning.

In terms of speaking as, possible, the top skill of communication, most participants explicitly stated that CLT emphasized oral skills. In one participant's interview, he even regarded 'communicate' a synonym of 'speak.' In the same vein, the other participants considered speaking the most essential skill to devote to when teaching. In all lessons, if possible, learning activities must include, either partially or as a whole, speaking practice/tasks in addition to managing speaking-rich environment from the beginning of the lesson. As Teacher D replied, "I design activities to let the kids speak English, practicing using English to communicate."

For interaction in class, the responses to the interviews indicate that the participants believed CLT requires face-to-face dyadic patterns of communication. This belief relates to their views of the significant role of speaking in CLT classrooms. Speaking activities from their viewpoints should be narrowed down to one-on-one oral communication through pair-work. An underlying reason was expressed through Teacher B's response, "Through pair work, I can have them practice speaking, doing role plays. Without this kind of activities, how can we claim that we implement CLT?"

In terms of what to focus when adopting CLT, all participants posited that both grammatical rules and the application of rules through skilled-based situations needed to be the pillars of teaching and learning. While most of them stated that they focused on linguistic functions, the others believed that CLT leans toward the use grammar in communication. Teacher $\mathrm{H}$, for instance, expressed her certainty that students should practice using English as a tool to communicate with other people. In doing this, communicative functions guide grammar choices. As captured in one of her lessons, she explicitly stated that students had to be able to ask and talk about healthy habits using the patterns and expressions How are you? What's wrong? and I am sorry to hear that. In contrast, for those who treat communicative activities as pseudo-authentic situations, students' interactions were just the opportunities for practice using grammatical rules for communication. Reminding students of an awareness of the correct form of grammar, Teacher $\mathrm{G}$ explicitly stated the necessity of correct usage, both before and during the controlled practice.

\subsection{How Do the Teachers Position Themselves in CLT Classrooms?}

Rooted from beliefs described in the previous section, the participants' roles reflected how they positioned themselves in CLT classrooms. Overall responses to the interview question indicated that CLT teachers could be viewed as designers. When planning a lesson, they manipulated ideas and experienced they gained when attending professional development workshops. They considered themselves designers, both adopting and adapting teaching strategies proposed by experts. Although activities recommended in teachers' manuals were available, they preferred to design themselves, to ensure the suitability and practicality. As Teacher D said during an interview, she enjoyed choosing, adapting, and even creating activities himself. Activities to use in English classes did not need to be long or complicated. Simple ones requiring students to ask and answer question in English might fit the immediate learning environment at that moment.

In addition to being designers, during each lesson, the participants played three prominent roles, presenters, managers, and coaches. For Teachers $\mathrm{C}$ and $\mathrm{H}$, with intension to create positive learning environments, they were 
willing to act as entertaining presenters. They believed that the teacher's personality and acting abilities are vital factors for effective CLT lessons. These might be more essential than the content and teaching methods, they added. As a presenter, the teacher needed to present clear instructions, explanations, and any other examples. Acting as presenters, they utilized creative activities that they believed would grab students' attention. That is to say, all must be fun.

To act as class managers, most teachers in this study said that CLT required the transitions of learning, practicing, and applying the language. Managers, as they positioned themselves, managed the flows through active management and problem solving skills. As students were frequently off-task, Teacher D, for instance, believed she served as a coach and consultant. Based on her clarification that was similar to Teachers F and G, the majority of her students tended to struggle when doing communicative activities. Without their immediate help, the students would struggle and that could lead to the failure of activities. As a coach in CLT scenarios, the teacher needed analysis skills and an understanding of students' needs, strengths, and weaknesses.

In addition, all teachers in this study reflected on themselves, especially on their English knowledge and proficiency. They were aware that CLT required teachers of high proficiency to be role models for the use of English. Using English as the medium of instruction throughout the lesson was sometimes stressful. Similarly, they raised issues regarding the discrepancies among the curriculum, school administrators' expectations, students' actual English knowledge, wide gaps of students' English proficiency, testing systems, and students' motivation in learning English, and differing values of teaching and learning English in Thailand. As practitioners working under demanding and the inconformity of these issues, the implementation of CLT was sometimes not rewarding at all.

The last image that the teachers reflected in the interviews was being problem-solvers. Teaching small classes was a task the participants wished they could have done. However, a class of more than forty students was reality. As Teacher D remarked in her second interview: "Large classes of 48 students were overwhelming. I have lots and lots of ideas to make my lessons fun and 'really' communicative. But with this large number, it is difficult for me. Instead of running smooth activities or promoting communicative lessons, I have to solve unexpected problems".

\subsection{What Are the Roles of a Knowledge Base in CLT Implementation?}

All teachers manipulated different aspects of a knowledge base when implementing CLT, but pedagogical content knowledge (PCK) as the most vivid. In a number of interviews, they mentioned about the CLT principles adopted into teaching strategies. Regarding this, it can be assumed that PCK was the most influential toward teaching practices and thoughts. For example, Teacher $\mathrm{C}$ explained the reason for integrating cooperative learning into group activities requiring his students to sort authentic materials based on the genres. Similarly, Teacher $\mathrm{H}$ applied running dictionary as a multi-skilled activity similar to real communication. Other examples include the use of video clips in English during presentation and lead-in phases. The participant justified the appropriateness of each video on the basis of the levels of complexity, vocabulary range, and speaking speed. These factors were compared against the students grade levels/proficiency, curriculum, and the lesson content.

Other two categories of knowledge base that always underlay teaching practices were content knowledge that includes knowledge of grammar as well vocabulary and communication skills, and subject matter knowledge. In one observed lesson, Teacher D integrated topics about pets, art, and English conversation. The details of animals' characteristics led to longer discussions. Also, Teacher F linked her personal knowledge about agriculture with vocabulary instruction when discussing the landscape of orchards and similar farm structures. These two aspects of knowledge base were also confirmed in their interviews.

\section{Discussion}

The findings from this study suggest further discussions. Firstly, CLT classrooms were found to share specific teaching and learning environments, with verbal interaction in English as a pillar. English was used extensively, even during non-instructional moments. One reason behind an attempt to maintain the use of English was that the teachers regarded speaking in English as the most important skill. It was not surprising that all communicative activities required students to speak. As perceived by the teachers in this study, 'speak' was equivalent to 'communicate.' It might be that communication must entail speaking. A few articles present issues on misconceptions due to beliefs about fluency over accuracy and oral skills as key part of communication. The findings in this study seem to be relatively relevant to this issue. The teachers were concerned with speaking while other skills received less attention (Richards, 2006). This is relatively relevant to a concern about teachers' misconception regarding CLT for teaching only speaking (Thompson, 1996 cited in Viet, 2008).

However, speaking activities tended to be aligned with the concepts and functions of either audio-lingual-based 
drills or the combination of mechanical and meaningful practice (Richards, 2006). Dialogue memorization and minimal changes of information outperformed other skills, due to the way the teachers perceived CLT. It can be argued that while CLT theoretically embraces all communicative skills, the implementation uncovered in this study leaned toward speaking as a sole skill.

Secondly, relevant to the concept of integrating form and meaning communicatively, the findings suggest that neither was devalued. Extended from above, since speaking was a goal of CLT, form or grammatical structure might serve as a tool to facilitate speaking. If this is true, it is likely that the teachers followed the 'weak' version, learning English to be able to communicate as a final goal, instead of the strong version that includes using English in real communication to enrich language learning. Guided by the concept they adopted, the teachers aimed at pushing productive skills, speaking in particular. Hence, not surprisingly, drawing students to review/revise grammar rules after the completion of activities was frequently abandoned.

The third segment of discussion relates to the teachers' reflection on their English competence. In line with previous studies, such as Ansarey's (2012), that found teachers to be concerned about their English proficiency, at least four teachers in this study raised this issue. Since they believed that they were supposed to use English as much as possible to form communication-rich learning environments, concerns about their language proficiency, at times, challenged CLT implementation. This concern can possibly impact the detail of CLT lesson designs, even limiting creative language activities. Similarly, selecting authentic materials to promote real, complex communication the classroom could be affected by the uncertainty of the teachers' confidence about their own English proficiency. As they perceived themselves as coaches when adopting CLT, concerns about insufficient English proficiency might also affect some elements of the lessons. All of these also relate to teacher's knowledge base. In all interviews, concerns about knowledge of English as how to teach effectively were clearly stated. This can be concluded that pedagogical content knowledge represented the participants' teaching practices supplemented by other areas.

\section{Conclusion}

This study aimed at uncovering teaching practices in naturalistic CLT-based classrooms, the teachers' reasons underlying the practices, and additional aspects reflected as practitioners implementing CLT. Classroom observations and face-to-face with a few additional telephone interviews conducted as data collection methods yielded rich sufficient data manipulated to the findings. In terms of teaching practices and associated characteristics of teaching and learning activities, four condensed themes including promoting 'small talk' in the target language, beginning the lesson with the combination of lead-in and presentation strategies, positively reacting to students' linguistic errors, and emphasizing semi-communicative activities. For reasons that shaped these practices, the teachers were found to be influenced by their beliefs regarding speaking as the priority of communication, face-to-face dyadic interaction as communication practice, and form and meaning as essential elements of teaching and learning English. While expressing additional opinions about CLT implementation, they viewed CLT teachers as teaching strategy designers, classroom entertainers, and necessarily problem solvers.

As indicated in the purposes, to uncover teaching practices and the teachers' reasoning that influenced the practices; this study is free from any evaluation or justification of the data drawn to answer the questions overarching the study. Limitations included the participants and the methodology. The participants included only eight Thai teachers regarding themselves as CLT proponents recruited based on the convenience and purposeful methods. They all voluntarily agreed to be engaged in the study. Also, the methodology was limited to classroom observations and interviews. Hence, further studies conducted in either similar or different contexts with different participants may yield different findings. The findings of this study contribute to the field of second language teacher education, both pre-service and in-service contexts. CLT interpretations displayed via teaching practices and teachers' opinions could serve this field as information for curriculum revision and any other professional development activities.

\section{Acknowledgments}

The author is thankful to the Faculty of Humanities, Srinakharinwirot University, for the research grant. Thanks also go to all teachers who voluntarily took part in this study.

\section{References}

Ansarey, D. (2012). Communicative Language Teaching in EFL Contexts: Teachers Attitude and Perception in Bangladesh. ASA University Review, 6(1), 61-78. Retrieved from https://pdfs.semanticscholar.org/ee95/2ff2f3b87d8782f7ee20242a3998f0127943.pdf

Bax, S. (2003). The end of CLT: a context approach to language teaching. ELT Journal, 57, 278-287. 
https://doi.org/10.1093/elt/57.3.278

Brown, H. D. (2007). Principles of language learning and teaching (5th ed.). White Plains, NY: Pearson Education.

Butler, Y. G. (2011). The implementation of communicative and task-based language teaching in the Asia-pacific region. Annual Review of Applied Linguistics, 31, 36-57. http://doi.org/10.1017/S0267190511000122

Canale, M., \& Swain, M. (1980). Theoretical Bases of Communicative Approaches to Second Language Teaching and Testing. Applied Linguistics, 1, 1-47. http://doi.org/10.1093/applin/I.1.1

Corbin, A., \& Strauss, A. (2008). Basic of qualitative research: Techniques and procedures for developing grounded theory (3rd ed.). Thousand Oaks, CA: Sage. https://doi.org/10.4135/9781452230153

Coskun, A. (2011). Investigation of the Application of Communicative Language Teaching in the English Language Classroom - A Case Study on Teachers' Attitudes in Turkey. Journal of Linguistics and Language Teaching, 2(1). Retrieved from https://files.eric.ed.gov/fulltext/ED513910.pdf

Frederickson, T. (2015). Thailand's English skills lagging, says training company. Bangkok Post. Retrieved from https://www.bangkokpost.com/learning/learning-news/756536/thai-english-proficiency-drops-now-3rd-wor st-in-asia-ef

Hiep, P. H. (2007). Communicative language teaching: unity within diversity. ELT Journal, 61(3), 193-201. https://doi.org/10.1093/elt/ccm026

Hsieh, H., \& Shannon, S. (2005). Three approaches to qualitative content analysis. Qualitative Health Research, 15, 1277-1288. https://doi.org/10.1177/1049732305276687

Hudson, R., Davis, C., Blum, G., Greenway, R., Hackett, J., Kidwell, J., ... Peck, C. (2016). A Socio-Cultural Analysis of Practitioner Perspectives on Implementation of Evidence-Based Practice in Special Education. The journal of Special Education, 50(10), 27-36. https://doi.org/10.1177/0022466915613592

Hymes, D. H. (1972). On Communicative Competence. In J. Pride, \& J. Holmes (Eds.), Sociolinguistics (pp. 69-293). Baltimore, USA: Penguin Education.

Jeon, J. (2009). Key issues in applying the communicative approach in Korea: Follow up after 12 years of implementation. English Teaching, 64(4), 123-150. https://doi.org/10.15858/engtea.64.4.200912.123

Koosha, M., \& Yakhabi, M. (2013). Problems Associated with the Use of Communicative Language Teaching in EFL Contexts and Possible Solutions. International Journal of Foreign Language Teaching \& Research, 1(2), 77-90. Retrieved from http://jfl.iaun.ac.ir/article_4185_bd99e90eb60e4a35bef452d8368acda1.pdf

Littlewood, W. (2013). Developing a Context-Sensitive Pedagogy for Communication-Oriented Language Teaching. English Teaching, 68(3), 3-25. https://doi.org/10.15858/engtea.68.3.201309.3

Liu, S. (2015). Reflections on Communicative Language Teaching and Its Application in China. Theory and Practice in Language Studies, 5, 1047-1052. http://doi.org/10.17507/tpls.0505.20

Mullock, B. (2006). The Pedagogical Knowledge Base of Four TESOL Teachers. The Modern Language Journal, 90(1), 48-66. https://doi.org/10.1111/j.1540-4781.2006.00384.x

Office of Basic Education Commission OBEC. (2015). CEFR-based manual for implementing teaching and learning English. Bangkok, Thailand: Ministry of Education.

Rahman, M. M., Singh, K. M., \& Pandian, A. (2018). Exploring ESL Teacher Beliefs and Classroom Practices of CLT: A Case Study. International Journal of Instruction, 11, 295-310. http://dx.doi.org/10.12973/iji2018.11121a.

Richards, J. C. (2008). Second language teaching education today. RELC Journal, 39, 158-168.

Savignon, S. (2018). Communicative Competence. In J. Liontas (Ed.), The TESOL Encyclopedia of English language teaching (pp. 1-7). Hoboken, NJ: John Wiley \& Sons.

Shulman, L. (1987). Knowledge and Teaching: Foundations of the New Reform. Harvard Educational Review, 57(1), 1-23. https://doi.org/10.17763/haer.57.1.j463w79r56455411

Spada, N. Coomunicative Language Teaching: current status and future prospects. In J. Cummins, \& C. Davison (Eds.), International handbook of English language teaching (pp. 271-288). New York: Springer. https://doi.org/10.1007/978-0-387-46301-8_20

Viet, K. A. (2008). Imperialism of communicative language teaching and possible resistance against it from 
teachers in Vietnam as an English foreign languages context. Journal of Science, Foreign Languages, 24,167-174.

Yang, H. (2011). Exploring Native and Non-native English Teachers' Integrated Pedagogical Content Knowledge and Instructional Practice: A Case Study of Four Teachers at a Taiwan University (Doctoral dissertation, The Ohio State University). Retrieved from https:/etd.ohiolink.edu/rws_etd/document/get/osu1292432768/inline

\section{Copyrights}

Copyright for this article is retained by the author(s), with first publication rights granted to the journal.

This is an open-access article distributed under the terms and conditions of the Creative Commons Attribution license (http://creativecommons.org/licenses/by/4.0/). 